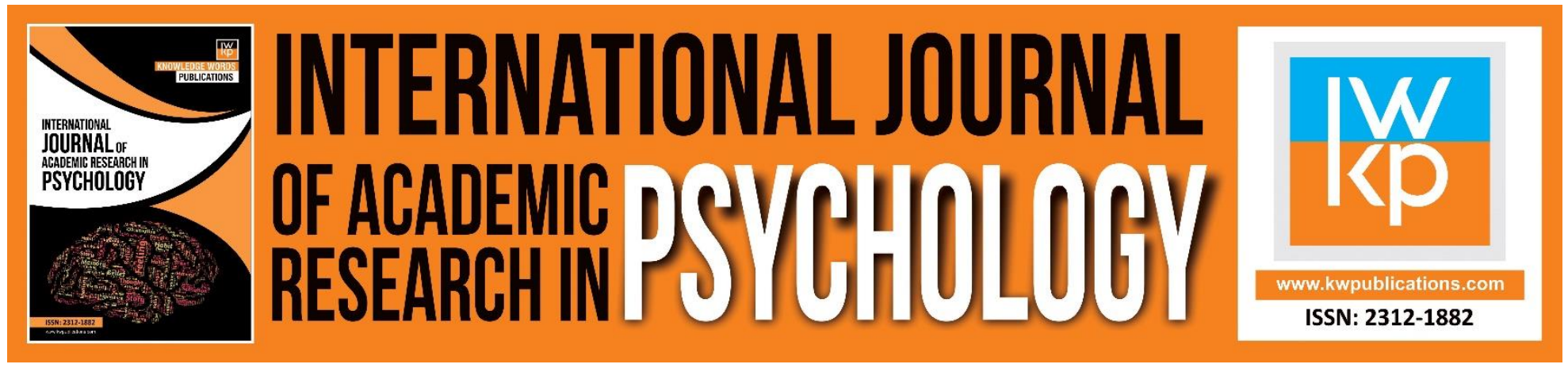

\title{
The Effectiveness of Social Skills Training on Self- Assertiveness and Academic Self- Efficacy of Dyslexic Students
}

Mohammad Shakeri, Leila Rahmati, Afsanehsadat Modabber, Maahdieh Eskandari

To Link this Article: http://dx.doi.org/10.46886/IJARP/v2-i1/1664

DOI: 10.46886/IJARP/v2-i1/1664

Received: 17 February 2015, Revised: 20 April 2015, Accepted: 11 May 2015

Published Online: 28 May 2015

In-Text Citation: (Shakeri et al., 2015)

To Cite this Article: Shakeri, M., Rahmati, L., Modabber, A., \& Eskandari, M. (2015). The Effectiveness of Social Skills Training on Self- Assertiveness and Academic Self- Efficacy of Dyslexic Students. International Journal of Academic Research in Psychology. 2(1), 20-27.

\section{Copyright: (c) 2015 The Author(s)}

Published by Knowledge Words Publications (www.kwpublications.com)

This article is published under the Creative Commons Attribution (CC BY 4.0) license. Anyone may reproduce, distribute, translate and create derivative works of this article (for both commercial and non-commercial purposes), subject to full attribution to the original publication and authors. The full terms of this license may be seen at: http://creativecommons.org/licences/by/4.0/legalcode

Vol. 2, No. 1, 2015, Pg. 20 - 27

https://kwpublications.com/journals/journaldetail/IJARP

JOURNAL HOMEPAGE

Full Terms \& Conditions of access and use can be found at https://kwpublications.com/pages/detail/publication-ethics 


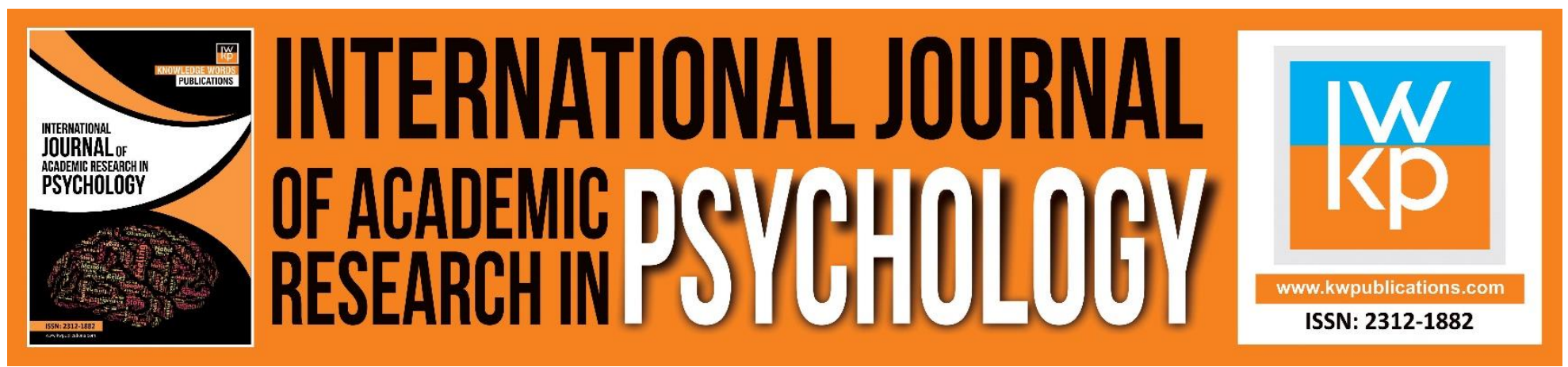

\title{
The Effectiveness of Social Skills Training on Self- Assertiveness and Academic Self- Efficacy of Dyslexic Students
}

\author{
Mohammad Shakeri ${ }^{1}$, Leila Rahmati², Afsanehsadat Modabber ${ }^{3}$, \\ Maahdieh Eskandari ${ }^{4}$ \\ ${ }^{1}$ Faculty Member, North Khorasan University of Medical Sciences, Bojnurd, Iran, ${ }^{2} \mathrm{MA}$ clinical \\ Psychology Islami Azadi University, Araq, Iran, ${ }^{3} \mathrm{MA}$ Clinical Psychology Islami Azadi University, Araq, \\ Iran, ${ }^{4}$ MA Clinical Psychology Islami Azadi University, Araq, Iran \\ Email: Leilarahmati2015@gmail.com
}

\begin{abstract}
Background: The dyslexic child is at risk the loneliness living and the lost of social discussion coequals partnership. The aim of this study was to determine the effects of social skills training on the SelfAssertiveness and academic self- efficacy of dyslexic students. Thirty students participated in the study. The experimental design was used in which 2 groups were compared on Pre test and post test measures by using Assertiveness Inventory (GRAQ, 1975) and Academic Self-efficacy Inventory. The experimental group was given 12 week training. The collected data were analyzed to the ANCOVA analyses. The results revealed that there were significant differences between the two groups based on Assertiveness scores ( $p$-value<0/001). However, there were significant differences found on Academic Self-efficacy scores between the two groups. Social skills training can significantly increase those aspects of Self- Assertiveness in Students with dyslexic.
\end{abstract}

Keywords: Social Skills, Self-Assertiveness, Academic Self- Efficacy, Dyslexic Students.

\section{Introduction}

The most important variables concerning the education development are self efficacy and SelfAssertiveness. Self efficacy means person's judgment about capabilities, capacities and abilities for an specific action (Bandura, 1977). Educational Self efficacy will cause the student to try self motivation in the environment through the internal motivation and obtain his efficient beliefs and behaves bravely. In recent years one of the most attractive variables for researchers has been the social abilities and its effect on the bravery and self efficacy of students which is due to the fact that the bravery is the main factor of inter personal relationships and the key of human connections(Lin et al., 2004). And has a very significant role in talents finding and the student creativity progress. Social abilities are some abilities that help people to have the positive interactions with others and 
continue them and involves connection establishment, problem solving, decision making, selfmanagement and relationships with other people in the same age (Aydogan, Klince, \& Tepetas, 2009) .Children who have learnt the social behavior are more efficient in connection establishment with other children(Asher \& Taylor, 2001) and social environment learning in comparison with children failing these social behaviors. These abilities assist children to have a more effective relationship with others .Normal children learn this ability in relationships with others like parents, sibling and peers ) without trying. But most of the dyslexic children encounter with negative reactions of adolescents and other children which is due to the failure of appropriate connection with friends. In recent years the researchers have attended the social abilities subject cause according to several investigations ,the lack of social abilities affect badly on students educational performance and intensifies problems of learning and obstacles the children development and results in the inappropriate events in the educational period. According to distinct investigations students with disorders in learning like dyslexic children defect in social information process (Bauminger \& Kimhi-Kind, 2008), weak interpersonal connections (Ladd \& Troop-Gordon, 2003; Wiener, 2004), social rejection levels and loneliness (Estell et al., 2008), adjustment problems with both internal and external kind (Al-Yagon \& Mikulincer, 2004; Sharma, 2004; Wiener, 2004).There are several investigations concerning social behaviors importance in people with specific needs like dyslexic children and according to the results ,social abilities are specially crucial for them .One of the crucial procedures for them is the social abilities training(Gresham, Sugai, \& Honer, 2001). There is no doubt in social capabilities importance in total change and adjustment of all children with special needs, in a way that the ability to make positive connections with adolescents and other people is one of the most important dimensions of each person change. The importance of appropriate social abilities in children success in classes has been proved several times(Gresham et al., 2001). The failure of appropriate social abilities is relevant to next problems in life like the failure in school,failure of employment or job loss, withdrawal and social isolation (Fantuzzo, Sekino, \& Cohen, 2004; Hyatt \& Filler, 2007). Generally, according to the investigations the social abilities interference necessity in dyslexic children is stated this way :social behavior lack is the most important factor of dyslexic children failure in social displacements and is the main reason of their job loss.Social behaviors training will decrease the level of inappropriate behaviors in classes like aggression and improve student personal relationship with others (Fraser, 2005; Kamps \& Kay, 2002; Kamps, Tankersley, \& Ellis, 2000). Social behavior training will decrease delinquency behaviors and will increase the inclusion of dyslexic children (Matson, Dempsey, \& LoVullo, 2008). Emotional and social change of children will increase their capacity for focusing on educational activities, improvement of general psychology health and behavioral problems decrease (Boo \& prins, 2007; Hennessey, 2007; Hill \& Furniss, 2006) .Generally the insufficiency in social abilities is relevant to the extended territory of problems like delinquency in the adolescence(Matson \& Wilkins, 2009) insufficiency of attention with the deficit of attention(Boo \& prins, 2007), change incapability, withdrawal and social isolation, challenging behavior (Matson \&Wilkins, 2009), school abandoning. According to the importance of Self-Assertiveness variables, educational efficacy and social abilities and the fact that there was no research concerning this subject on dyslexic children in Iran and the fact that the failure of appropriate social behaviors to make positive connections will cause the dyslexic children the withdrawal and social rejection ,one of the best options for these people to become sociable and capable of showing existence tools and efficacy in the society is the social abilities training. Therefore this research is dedicated to study the affect of social abilities 
INTERNATIONAL JOURNAL OF ACADEMIC RESEARCH IN PSYCHOLOGY

Vol. 2, No. 1, 2015, E-ISSN: 2312-1882 @ 2015 KWP

training on the self educational efficacy and the existence tools of dyslexic students in the schools of Teheran city.

\section{Materials and Methods}

The present research is a semi-experimental research with pretest - post test design with control group. The target population for this study was students with dyslexia, ages 12-16 years-old who was studying schools of Tehran city during the 2013-2014 academic years. The studied people in the research were 30 male students. In this research multistage cluster random sampling was used. At first one region was chosen randomly among Tehran's regions and then among educational areas of that region one region was chosen randomly. Then two schools were selected from male schools. Considered sample was chosen randomly. Then randomly assigned to an experimental and a control groups. The experimental group received social skills training two times a week and total sessions lasted in two months all training session were conducted by researcher at the school.

The Assertion Inventory: (Al; Gambrill \& Richey, 1975). The Al is a 40-item self-report questionnaire that assesses discomfort and response probability concerning assertive responding in a range of situations that demand an assertive response. For each item the respondent is requested to indicate the degree of discomfort or anxiety on a 5-point

scale that ranges from I (none) to 5 (very much) and to indicate the probability of displaying the behavior if actually presented with the situation on a 5-point scale ranging from 1 (always do it) to 5 (never do it). The scale has been shown to have good test-retest reliability, and discomfort scores have been shown to discriminate adequately between unassertive and assertive college students. Furthermore, improvement in discomfort scores has been found following AT. The assessment of both discomfort and response probability allows identification of different subgroups of clients. In our study, subjects were selected on the basis of a combination of high discomfort and low response probability.

Academic Self Efficacy :scale is an Indonesian version instrument that intended to asses the level of student's efficacy in regards with academic environment. Consists of 15 items this scale was developed by Rahardjo (2012) based on self-efficacy dimensions from Bandura, which reflect one's person Magnitude, Strength and Generality as a student. An adjusted scale was intended to academic environment. The responses alternatives were presented of six grades scale that extended from strongly agree into strongly disagree.

First the intervention and control groups were examined by the social skill subscales. The two groups were compared and no significant difference was found in the variable like IQ and age.

Intervention group was received the social skills training at 2 months, in 12 sessions. Training was conducted through a program that included coaching, feedback, modeling, and role playing and making chips. It is worth mentioning that during the intervention, children in control group did not receive special training and proceeded to perform daily activities. The skills that were trained during 12 sessions in the intervention group included: Greet and introduce themselves to the others, To allow others to use their devices, Follow the instructions and rules, Attention to others speaking, To apologize when doing mistake, To cooperate with friends, Maintenance of school facilities 
INTERNATIONAL JOURNAL OF ACADEMIC RESEARCH IN PSYCHOLOGY

Vol. 2, No. 1, 2015, E-ISSN: 2312-1882 @ 2015 KWP

At the end of training period, and 2 months later, all subjects were evaluated again by above measure. The intervention program attempts to increase understanding of social skills in boys with dyslexia, and attention to improving Self- Assertiveness and academic self- efficacy functioning.

The SPSS version 21 was used to statistical analysis of data, and ANCOVA analyses test was used to examine relationships between variables.

\section{Results}

30 children with dyslexia participated in this research. The youngest child was 12 years old and the oldest one 15 years old. The Statistical indexes of the subjects' age concerning the group have been reported in Table 1.

Table 1: Descriptive indexes of the subjects' age concerning the group:

\begin{tabular}{llllllll}
\hline Groups & $\mathbf{N}$ & Max & Min & $\mathbf{M}$ & SD & $\mathbf{t}$ & $\mathbf{P}$ \\
\hline Experimental & 15 & 15 & 12 & 9.34 & 2.12 & .193 & .834 \\
Control & 15 & 15 & 12 & 9.12 & 2.30 & & \\
\hline
\end{tabular}

Regarding the written figures in Table 1, the average of the subjects' age of the experimental group was more compared to the control group. The isotropy of the control and experimental groups in the age average was analyzed through the statistical test called Independent T. There was not the significant statistical difference in the subjects' age average in control and experimental groups ( $p=$. / 834)

Table 2: Descriptive indices of Self- Assertiveness and self- efficacy for experimental and control groups in pretest and posttest situations

\begin{tabular}{cccccccccc}
\hline & \multicolumn{4}{c}{ Experimental group } & \multicolumn{3}{c}{ Control group } \\
\hline Variable & \multicolumn{3}{c}{ Pretest } & \multicolumn{2}{c}{ Posttest } & & Pretest & & Posttest \\
& & & & & & & & \\
& $M$ & SD & M & SD & M & SD & M & SD \\
Self- & 105.4 & 11.58 & 135.8 & 14.53 & 101.63 & 13.54 & 99.2 & $\mathbf{1 4 . 2 3}$ \\
Assertiveness & 3 & & & & & & & \\
self- efficacy & 122.2 & 13.26 & 144.5 & 17.55 & 124.86 & 14.032 & 123.46 & $\mathbf{1 5 . 8 8}$ \\
\hline
\end{tabular}

As Table 2 shows there are some differences between the average of control group and experimental one in the research variables; but being significant of these differences is not clear to us. Then for comparing the group the ANCOVA analyses has been used regarding the existence of some dependent variables and their interval nature and also the performance of pre test. 
INTERNATIONAL JOURNAL OF ACADEMIC RESEARCH IN PSYCHOLOGY

Vol. 2, No. 1, 2015, E-ISSN: 2312-1882 @ 2015 KWP

Table 3: The results of ANCOVA for comparing Self-Assertiveness and self- efficacy in two groups

\begin{tabular}{cccccccc}
\hline $\begin{array}{l}\text { Source of } \\
\text { change }\end{array}$ & $\begin{array}{c}\text { Dependent } \\
\text { variable }\end{array}$ & SS & Df & MS & F & Sig & $2 \eta$ \\
\hline group & $\begin{array}{c}\text { Self- } \\
\text { Assertiveness } \\
\text { self- efficacy }\end{array}$ & 1024.34 & 1 & $567 / 46$ & $67 / 46$ & $0 / 001$ &.$/ 80$ \\
& 152734. & 1 & $758 / 34$ & $45 / 36$ & $0 / 001$ &.$/ 67$ \\
\hline
\end{tabular}

ANOVA revealed There was statistically significant difference between the two groups at $p=0 / 001$ with and 'f value of $67 / 46$

The ANOVA analysis shows that the difference between them is significant at .05 level, therefore occurred by chance.

\section{Discussion}

The purpose of this study was the effectiveness social skills Training on Self- Assertiveness and academic self- efficacy of dyslexic students. The results revealed that there were significant differences between the two groups based on Assertiveness scores. However, there were significant differences found on Academic Self-efficacy scores between the two groups. In other words, the level of the self assertiveness and the academic self efficacy of dyslexic students of experiment group have increased considerably in comparison with the pre training period. According to the results of diverse investigations, dyslexic students defect in social abilities processing, weak interpersonal abilities, high level of social rejection and loneliness, disorders of behaviors and depression, less intimate friends ,high level of aggressive behaviors, disruption of interpersonal relationships, different problems concerning interpersonal conflicts, adjusting problems and the low level of positive social behaviors .Describing this issue, diverse problems that dyslexic students manifest interacting with social behaviors, is due to the lack of the leadership and positive social abilities maintenance. Actually the lack of appropriate social abilities will decrease the self assertiveness and self efficacy of students .Describing this issue, the self assertiveness and academic self efficacy of these students has lowered which is due to the weakness of the interactive and nonverbal abilities and attending the fact that this ability is one of the main factors of social abilities. On the other hand, it is possible to mention that these students have lower grades in social behaviors establishment in comparison with the other students because they utilize the aggressive pattern and the weak isolation pattern and the lack of ability to decode the nonverbal signs in social behaviors and this lack will result in the self assertiveness and the academic self efficacy. The possible reason of increasing the self assertiveness level of dyslexic students in the acquisition and application of the social behaviors, is a foundation on which the individual relationships are constructed. Students who learn the social behaviors truly, practice and apply their competence, will succeed in friends finding and memberships of friends groups, have positive interactions with their friends and show a range of acceptable behaviors .Dyslexic students who learn the social behaviors well and learn the rules of their friends groups and establish positive and strong relationships with the family members and the society, mostly will show the high level of the self assertiveness and the academic self efficacy. In fact dyslexic students who learn social behaviors well and show appropriate behaviors socially have a more positive self concept 
INTERNATIONAL JOURNAL OF ACADEMIC RESEARCH IN PSYCHOLOGY

Vol. 2, No. 1, 2015, E-ISSN: 2312-1882 @ 2015 KWP

which will result in the high level of the self assertiveness and recognizing limitations and capabilities of their own and an appropriate academic self efficacy. The social behavior application influences the improvement and regulation of interpersonal relationship, social responsibilities acceptance ,correct decision making and conflict solution and it is possible to obtain these aims only by teaching the fundamental abilities to the dyslexic students. Social abilities training will improve the abilities regarding the self assertiveness and concerning this issue, the weak social abilities of dyslexic students will harm their self assertiveness and academic self efficacy which will exacerbate their situation by their consecutive fails in the school and the incorrect comparison between them and their friends. In fact the social behavior training can increase the level of the self assertiveness and self efficacy of students by providing applicable sources (verbal encourages and individual experiences).When a student can assert himself in the class and can ask his question without any shame and stress of the class population or the teacher and states his opinions in the class or be able to assert himself in the class and manifest his academic capabilities, will increase his functionality .It is possible to recognize 75 percent of dyslexic students by their lower social ability in comparison with other children ,so according to the findings of this investigation, it is recommended to add the social abilities in their academic and therapeutic programs .

\section{Acknowledgements}

The authors would like to thank the children, schools, the managements and all those who participated in the study

\section{References}

Al-Yagon, M., \& Mikulincer, M. (2004). Patterns of close relationships and socioemotional and academic adjustment among school-age children with learning disability. Learning Disabilities Research \& Practice, 19, 12-19.

Asher, S., \& Taylor, A. (2001). The social outcomes of mainstreaming : sociometric assessment and beyond. Exceptional children quarterly, 12, 1239.

Aydogan, Y., Klince, F. E., \& Tepetas, S. (2009). Identifying parent views regarding sicial skills. procedia social and behavior ciences, 1(2009), 1507-1512.

Bandura, A. (1977). Self- efficacy: The exercise of control. New york: Freedman.

Bauminger, N., \& Kimhi-Kind, I. (2008). Social information processing, security of attachment, and emotion regulation in children with learning disabilities. Journal of Learning Disabilities,, 41, 315-332.

Boo, G. M., \& Prins, P. J. M. (2007). Social skills competence in children with ADHD: Possible moderators and mediators in social skills training. Clinical Psychology Review, 27, 78-97.

Estell, D. B., Jones, M. H., Pearl, R. A., Van Acker, R., Farmer, T. W., \& Rodkin, P. R. (2008). Peer groups, popularity, and social preference: Trajectories of social functioning among students with and without learning disabilities. Journal of Learning Disabilities,, 41, 5-14.

Fantuzzo, J., Sekino, Y., \& Cohen, H. L. (2004). An examination of the contributions of interactive peer play to salient classroom competencies for urban head start children. Psychology in the Schools, 41, 323-336. 
INTERNATIONAL JOURNAL OF ACADEMIC RESEARCH IN PSYCHOLOGY

Vol. 2, No. 1, 2015, E-ISSN: 2312-1882 @ 2015 KWP

Fraser, W. M. (2005). Social information-processing skills training to promote social competence and prevent aggressive behavior in the third grade. Journal of Consulting and Clinical psychology, 73(6), 1045-1055.

Gresham, F. M., Sugai, G., \& Honer, R. H. (2001). Interpreting outcomes of social skills training for students with high-incidence disabilities. Exceptional children quarterly, 67(3), 331-334.

Hennessey, B. A. (2007). Promoting social skills competence in school-aged children: The effects of the open circle program. Journal of School Psychology, 45, 349-360.

Hill, J., \& Furniss, F. (2006). Patterns of emotional and behavioral disturbance associated with autistic traits in young people with severe challenging behavior. Research in Developmental Disabilities., 28, 164-173.

Hyatt, K. H., \& Filler, Y. W. (2007). A comparison of the effects of two social skills training approaches on teacher and child behavior. Journal of Research in Childhood Education, 22, 85-93.

Kamps, D. M., \& Kay, P. (2002). perventing problem through social skills instruction. in B. Algozzin, \& p. kay (Eds), preventing problems Behavior: A Handboo of successful pervention strategies. CA: Corwin press.

Kamps, D. M., Tankersley, M., \& Ellis, C. (2000). Social skills interventions for young at-risk students: A 2-years follow-up study. Behavioral Disorders, 25, 310-324

Ladd, G. W., \& Troop-Gordon, W. (2003). The role of chronic peer difficulties in the development of children's psychological adjustment problems. Child Development, 74, 1344-1367.

Lin, Y. R., Shiah, I. S., Chang, Y. C., Lai, T. J., Wang, K. Y., \& Chou, K. R. (2004). Evaluation of an assertiveness training program on nursing and medical students' assertiveness, self-esteem, and interpersonal communication satisfaction. Nurse Education Today, 24, 656-665.

Matson, J. L., Dempsey, T., \& LoVullo, S. V. (2008). Characteristics of social skills for adults with intellectual disability autism and PDD-NOS. Research in Autism Spectrum Disorders, 3, 207213.

Matson, J. L., \& Wilkins, J. (2009). Psychometric testing methods for childre's social skills. Research in Developmental Disabilities., 30, 249-274.

Sharma, G. (2004). A comparative study of the personality characteristics of primary school. Students with learning disabilities and their non-learning disabled peers. Learning Disability Quarterly, $27,127-140$.

Wiener, J. (2004). Do peer relationships foster behavioral adjustment in children with learning disabilities? Learning Disability Quarterly, 27, 21-30. 